\title{
Effect of Eight Weelss of Aerobic Exercise on Iron Status and Coagulation and Immune Indices in Non-Athlete Females
}

\author{
Nahid Bijeh (PhD) \\ Department of Sport Physiology, \\ Faculty of Physical Education and \\ Sport Sciences, Ferdowsi University of \\ Mashhad, Mashhad, Iran \\ Asra Askari (PhD) \\ Department of Physical Education, \\ Islamic Azad University, Gorgan \\ branch, Gorgan, Iran \\ Saeed Ramezani(PhD) \\ Faculty Member of Physical Education \\ and Sport Sciences, Payame Noor \\ University, Iran \\ Babisan Askari (PhD) \\ Department of Physical Education, \\ Islamic Azad University, Qaemshahr \\ branch, Qaemshahr, Iran \\ Corresponding author: Dr Nahid \\ Bijeh \\ Tel: +989155072745 \\ Email: bijeh@ferdowsi.um.ac.ir \\ Address: Faculty of Physical \\ Education and Sport Sciences, \\ Ferdowsi University of Mashhad, \\ Mashhad, Iran \\ Received : 04 May 2015 \\ Revised: 01 Jun 2015 \\ Accepted: 02 Jun 2016
}

\begin{abstract}
Background and objectives: The aim of this study was to investigate the effect of eight weeks of aerobic exercise on serum iron, serum ferritin, platelet count, mean platelet volume, and some immunity indices in non-athlete females.

Methods: In this study, 30 non-athlete females aged 30-45 years were randomly divided into an experimental and a control group. The experimental group was subjected to perform aerobic exercise at $60-70 \%$ of maximal heart rate for eight weeks, three sessions per week and one hour per session. Blood parameters were measured before the exercise program and after the completion of program by taking $2 \mathrm{ml}$ blood samples from the venous vein of the participants in the sitting position. Finally, t-test was used to compare the pretest and post-test means of each group and independent t-test was used to compare the two groups at significance of 0.05 .

Results: After eight weeks of aerobic exercise, there was a significant increase in mean platelet volume and a significant decrease in serum iron and ferritin levels in the experimental group $(\mathrm{P}<0.05)$. There was a slight decrease in the number of platelets, white blood cells, granulocytes, monocytes and lymphocytes $(\mathrm{P}<0.05)$.

Conclusion: We recommend physical education instructors, athletes and nonathletes to consider iron supplementation during aerobic exercise, and modify appropriate training intensity based on the fitness and age of trainees to prevent risk of anemia.

Keywords: Aerobic exercise, platelet, iron, ferritin, white blood cell.
\end{abstract}




\section{INTRODUCTION}

Physical exercise facilitates increase in physical performance and maximal oxygen consumption $\left(\mathrm{VO}_{2} \max \right)$ and changes in the body's erythrocytic and immune systems (1, 2 ). Iron is a rare mineral element that plays essential roles in the human body (3). It also crucial for optimal athletic performance, and delays muscular fatigue, increases $\mathrm{VO}_{2}$ max, and decreases concentration of blood lactate (4). A study reported that eight weeks of rehabilitation aerobic exercise at $55 \%$ of the $\mathrm{VO}_{2}$ max significantly reduces the concentration of ferritin and iron in patients with thalassemia major (5). Recent studies have shown that abnormalities in blood indices could be risk factors for coronary heart disease, especially arterial occlusive disease (6). Platelets play a major role in the pathophysiology of cardiovascular disease, thrombogenesis associated with atherosclerosis, and plaque formation mechanisms $(7,8)$. Although platelets are essential for normal blood coagulation, recent evidence suggests that abnormal function, accumulation and activation of platelets play a crucial role in acute coronary artery disease, myocardial infarction, unstable angina, and heart attack (9). It has been demonstrated that intense exercise can temporarily increase the incidence of primary heart attack and elevates the risk of thrombosis in cerebrovascular events $(10,11)$. Intense exercise stimulates the prothrombotic state, which may cause sudden cardiac arrest and acute myocardial infarction (12). On the other hand, intense exercise activity increases platelet function $(9,10)$. In this regard, a study showed that four weeks of kickboxing training significantly increases platelet count and mean platelet volume (MPV) (13). In recent years, the impact of physical activity on the immune system has been investigated by several studies. These studies have examined the effects of exercise on function of the immune system as well as other physical stressors such as burns, surgery, and acute myocardial infarction (14). Wu et al. reported a significant increase in white blood cell (WBC) count and a significant reduction in number of lymphocytes, and no change in monocytes immediately after an ultramarathon race (15). The effects of exercise on hematological variables, especially immune responses, have been debated in many studies. Given that a wide range of factors could influence immune responses to exercise, the importance of the immune system in maintaining the health of athletes, and the role of iron deficiency in reduced exercise in women, we aimed to investigate effects of eight weeks of aerobic training on hematological profile of non-athlete females aged 30 to 45 years.

\section{MATERIAL AND METHODS}

This semi-experimental study was done on 30 non-athlete females aged 30-45 years from Galoogah (Iran). Participants were not taking any medication and had no history of diabetes, hypertension and cardiovascular disease. Based on matched subject design and a walking test of 1600 meters, the participants were divided into an experimental and a control group. To monitor the diet, the participants first completed a 3-day dietary questionnaire, which was standardized by the Tehran University of Medical Sciences with acceptable validity and reliability (16).

Then, data were analyzed using the Food Processor Nutrition Analysis software. After preliminary assessment of daily energy intake, the type and amount of food required for each person were recommended based on the dietary habits.

\section{Exercise protocol}

The experimental group performed one hour of aerobic exercise at $60-70 \%$ of maximum heart rate for eight weeks, three sessions a week. Before each session, the participants warmed up for 10-15 minutes, and each session ended with 5-7 minutes of cool down.

In the first week, the participants performed fast-walk repeatedly, along with stretching and jumping movements. In the second week, they ran for 2 minutes with four repetitions in two sets and in the eighth week they ran for 5 minutes with four repetitions in two sets.

To measure the blood parameters, fasting blood sample $(2 \mathrm{ml})$ was taken from brachial vein of participants before and after the completion of the 8-week aerobic exercise.

\section{Statistical analysis}

Given the normality and homogeneity of the data, dependent t-test was used to compare the pre- and post-test data for each group and independent t-test was used to compare the groups. All statistical analyses were performed using SPSS (version 18) and at significance of 0.05 . 


\section{RESULTS}

The physical characteristics of the participants in both study groups are presented in Table 1. After the 8-week aerobic exercise, iron and ferritin levels decreased significantly in the experimental group, while MPV increased significantly $(\mathrm{P}<0.05)$. However, the platelet count in the experimental group did not change significantly (Table 2). The number of WBCs, granulocytes and monocytes reduced slightly, while the number of lymphocytes increased slightly $(\mathrm{P}>0.05)$.
According to Table 3, mean values for MPV and ferritin decreased in both groups in the post-test stage. However, the decrease was statistically significant only in the case of MPV. In the experimental group, the values for WBCs, granulocytes and platelets decreased slightly in the post-test, while the levels of lymphocytes and monocytes increased slightly. There was no statistically significant difference observed in these values between the two study groups.

Table1- Physical characteristics of the subjects in both study groups

\begin{tabular}{ccc}
\hline Characteristic & Control group & Experimental group \\
\hline Height $(\mathrm{cm})$ & $\mathbf{1 5 8 . 0 6} \pm 6.35$ & $\mathbf{1 5 8 . 5 3} \pm 3.54$ \\
Weight $(\mathrm{Kg})$ & $\mathbf{7 4 . 8 6} \pm 12.39$ & $\mathbf{7 1 . 9} \pm \mathbf{1 2 . 6 8}$ \\
Age & $39.93 \pm 4.39$ & $36.86 \pm 4.77$ \\
\hline
\end{tabular}

Table 2 -Mean and standard deviation (SD) of dependent variables for the experimental group in the pre- and post-test stage

\begin{tabular}{|c|c|c|c|}
\hline \multirow[t]{2}{*}{ Variable } & \multicolumn{3}{|c|}{ Experimental group } \\
\hline & pre-test & post-test & P-value \\
\hline Ferritin $(\mu \mathrm{g} / \mathrm{L})$ & $49.98 \pm 25.20$ & $38.37 \pm 31.88$ & $* 0.001$ \\
\hline Iron $(\mu \mathrm{g} / \mathrm{dl})$ & $90.34 \pm 21.48$ & $71.44 \pm 20.76$ & $* 0.011$ \\
\hline $\begin{array}{l}\text { Mean latelet } \\
\text { volume (fL) }\end{array}$ & $7.12 \pm 2.48$ & $9.34 \pm 3.66$ & $* 0.004$ \\
\hline $\begin{array}{c}\text { Number of } \\
\text { platelets }(K / \mu L)\end{array}$ & $229.53 \pm 18.7$ & $228 \pm 12.47$ & 0.946 \\
\hline Lymphocyte (\%) & $50.53 \pm 15.03$ & $52.43 \pm 8.95$ & 0.57 \\
\hline Monocyte (\%) & $1.90 \pm 1.29$ & $1.35 \pm 0.86$ & 0.19 \\
\hline \multirow{2}{*}{$\begin{array}{l}\text { Granulocyte } \\
\text { WBC }(K / \mu L)\end{array}$} & $49.55 \pm 12.50$ & $45.61 \pm 8.75$ & 0.16 \\
\hline & $5.92 \pm 1.48$ & $5.83 \pm 1.29$ & 0.82 \\
\hline
\end{tabular}

Table 3- Mean and SD of dependent variables for the study groups in the post-test stage

\begin{tabular}{|c|c|c|c|}
\hline Variable & Control group & Experimental group & P-value \\
\hline Ferritin $(\mu \mathrm{g} / \mathrm{L})$ & $78.93 \pm 25.20$ & $38.37 \pm 31.88$ & 0.069 \\
\hline Iron $(\mu \mathrm{g} / \mathrm{dl})$ & $98.23 \pm 27.76$ & $71.44 \pm 20.76$ & *0.026 \\
\hline $\begin{array}{c}\text { Mean latelet volume } \\
\text { (fL) }\end{array}$ & $12.54 \pm 4.76$ & $9.34 \pm 3.66$ & $* 0.006$ \\
\hline $\begin{array}{l}\text { Number of platelets } \\
\qquad(K / \mu L)\end{array}$ & $243.33 \pm 10.48$ & $228 \pm 12.47$ & 0.71 \\
\hline Lymphocyte (\%) & $49.94 \pm 6.89$ & $52.43 \pm 8.95$ & 0.40 \\
\hline Monocyte (\%) & $0.95 \pm 0.51$ & $1.35 \pm 0.86$ & 0.13 \\
\hline \multirow{2}{*}{$\begin{array}{l}\text { Granulocyte } \\
\text { WBC }(K / \mu L)\end{array}$} & $49.09 \pm 7.12$ & $45.61 \pm 8.75$ & 0.24 \\
\hline & $6.78 \pm 1.6$ & $5.83 \pm 1.29$ & 0.08 \\
\hline
\end{tabular}




\section{DISCUSSION}

In the experimental group, eight weeks of aerobic exercise caused a minor decrease in WBCs, granulocytes and monocytes, but increased the level of lymphocytes slightly. These results are inconsistent with the findings of some other studies $(15,17,18)$. It is believed that immune responses during and after exercise rely on several factors including release of catecholamines, pituitary-adrenal axis, and feedback of immune cells. In addition, other factors such as intensity and duration of exercise, local muscle injury, metabolic changes, cortisol release, and increased body temperature could be associated with exercise-induced change in the immune response (19). According to most studies, the intensity and duration of exercise can have different effects on the immune indices, indicating that moderate-intensity exercise imposes less stress on the immune system compared to long-term and intensive exercise. On the other hand, immunological studies have shown the involvement of many other mechanisms, stating that the release of stress hormones (cortisol and epinephrine), hemodynamic changes, and increase in body temperature mediate immune responses. In addition, neutrocytosis and lymphocytosis have a major role in this regard $(6,17,18)$. Findings of Mcfarlin et al. showed that a period of aerobic exercise significantly increases the number of WBCs (17).

It has been suggested that reduced number of monocytes following long-term exercise may indicate adaptation to intensive exercise because monocytes produce some inflammatory mediators (such as interleukin1and prostaglandins), and this reduction in the number of monocytes ultimately influences these mediators. Low level of leukocytes may be due to exercise-induced increase in plasma volume (20). Hasani et al. reported a significant decrease in the number of monocytes and WBCs and no significant change in platelet count following six weeks of progressive endurance training in nonathlete healthy men (21). One of the reasons for the increase in lymphocyte count in the experimental group is the reduction of plasma glutathione levels, which may occur during aerobic exercise. Given that glutamine is important for rapid division of lymphocytes, the reduction of plasma glutathione levels may limit the proliferation of lymphocytes or other immune cells (22). During long-term exercise at moderate intensity, the contribution of lymphocytes to the increase in leukocytes is minimal, although the number of lymphocytes gradually increases compared to baseline (23). Generally, the possible mechanisms that can increase leukocyte count after intensive exercise could be due to different hormonal effects on secretion, margination and emigration of WBCs (24). In other words, these changes are probably related to catecholamines, cortisol and some chemotactic factors since transient immunological impairment occurs under such conditions (15). Nevertheless, its exact mechanism during exercise is unknown, but it is likely that some mechanical factors such as increased cardiac output and changes in endothelial cells of capillaries are involved in this process. In the resting state, less than half of the adult leukocytes are circulating in the cardiovascular system, a process known as demargination (25). Finally, the insignificant change in number of immune cells following the exercise intervention can be attributed to training condition, duration, severity, type of exercise, age, gender, ethnicity, diet, and type of muscle fibers involved. We also found that the aerobic exercise program caused a significant decrease in the level of ferritin and iron in the experimental group, which is consistent with the findings of some other studies $(3,26)$. However, two studies have reported that ferritin increases significantly following a period of aerobic exercise $(27,28)$. A study on 39 female students showed that eight weeks of aerobic training at $70-80 \%$ of maximal heart rate significantly reduced ferritin level (29). In study of Di Santolo, ferritin level in female athletes who had three months of regular training had no difference with control participants. They believed that this could be attributed to the type of activity (aerobic or anaerobic) (30). Ramezanpour also reported a significant decrease in serum iron and ferritin levels after six weeks of aerobic training in young females (4). The body iron level is affected by hemolysis of red blood cells, increased body temperature, urinary iron excretion or sweat, and gastrointestinal bleeding. Inadequate intake of iron through diet ultimately leads to the use of iron stored as ferritin, resulting in ferritin reduction (31). In other words, serum ferritin can be reduced 
by intravascular hemolysis following exercise training, particularly in aerobic and endurance trainings. Another reason for the reduction in ferritin could be the gender of participants, as it is known that females can suffer from iron deficiency after mensuration and/or pregnancy (26, 28-32). Our results are inconsistent with the results of other studies, which could be because majority of studies has been conducted on athletes, while our participants were non-athlete who may require longer and more intense trainings, at least at this age range $(26,28-32)$. The results of this study showed that the eight weeks of aerobic exercise had no significant impact on platelet count in the experimental group (only a minor reduction). In addition, the platelet count had no significant difference between the two groups. In line with our findings, Ricci et al. stated that aerobic exercise has no significant effect on platelet count. However, two studies showed that aerobic exercise significantly increases platelet count $(34,35)$. Inconsistent with our findings, Coppola et al. reported that aerobic training significantly reduces platelet count (36). These inconsistencies could be related to gender of the participants, duration of the exercise, and type of exercise. Generally, platelets play an important role in the coagulation process and are involved in modulation of inflammatory processes while interacting with leukocytes $(37,38)$. One should not neglect the acute effect of exercise that causes hemoconcentration. On the other hand, adaptation to physical activity causes

\section{REFERENCES}

1. Szygula Z. Erythrocyte system under the influence of physical exercise and training. Sports Med. 1990; 10(3):181-97.

2. Rahmaninia F, Damirchi A, Mousavi SH. The comparison of two types of physical activities on serum iron levels, serum ferritin and transferrin receptor in athletic woman. Olympic. 2005; 13(2): 227-231.[Persian]

3. Alikarami H, Nikbakht $M$, Valipour Dehnou V, Ghalavand A. Effect of 8 Weeks of Continuous Moderate Intensity Aerobic Training on Iron Status in ClubLevel Football Players. Horizon of MedicalSciences.2017;23(2):129-133.

4. Ramezanpour MR, Kazemi M. Effect of aerobic training along with iron supplementation on the hemoglobin, red blood cells, hematocrit, serum ferritin, transferring and iron in young girls. Komesh J. 2012; 13(2): 233-239.[Persian]

5. Vashtani S H, Nazem F, Bordar F. The effect of aerobic rehabilitation program on concentration of Ferritin, Iron, TIBC and cardiovascular operation, the hemodilution, which decreases platelet volume. It is thought that the main mechanism for the reduction of platelet count could be related to increase or maintenance of the blood $\mathrm{pH}$ following adaptation to exercise $(39,40)$. We found that the eight weeks of aerobic exercise significantly increased MPV in the experimental group. Moreover, MPV values were significantly different between the experimental group and the control group, which could be associated with the reduction in plasma volume $(41,42)$. Evaluation of MPV can help determine the degree of platelet changes, and could be used as a simple index and a strong biological variable for platelet activation (43).

\section{CONCLUSION}

The results of this study showed that the 8 -week aerobic exercise could affect iron status. We recommend physical education instructors, athletes and non-athletes to consider iron supplementation during aerobic exercise, and modify appropriate training intensity based on the fitness and age of trainees to prevent risk of anemia.

\section{ACKNOWLEDGEMENTS}

We would like to extend our sincere gratitude to the research staff and study subjects in the city of Galogah for their cooperation.

\section{CONFLICT OF INTEREST}

The authors declare that there is no conflict of interest.

young patients suffering from major thalassemia. Guilan Uni Med Sci. 2009; 18(71): 95-102. [Persian]

6. El-sayed M, Ali N, El-Sayed Ali Z. Haemorheology in exercise and training. Sports Med. 2005; 35(8): 649-670. 7. Williams MS, Kickler TS, Vaidya D, Ng'alla LS, Bush DE. Evaluation of platelet function in aspirin treated patients with CAD. J Throm Thrombolysis. 2006; 21(3): 241-247.

8. Aruigemma C, Fattorossi A, Sestito A, Sgueglia GA, Farneti S, Buzonetti A. Relationship between changes in platelet reactivity and changes in platelet receptor expression inducedby physical exercise. Thrombosis Research. 2007; 120(6): 901-909. 23.

9. El-sayed M, Ali N, El-Sayed Ali Z. Aggregation and activation of blood platelets in exercise and training. Sports medicine. 2005; 35(1): 11-22.

10. Singh I, Quinn H, Mok M, Sinclair AG, Hawley JA. The effect of exercise and training status on platelet activation: Do cocoa polyphenols play a rol?. Platel. 2006; 17(6): 361-367. 
11. Wang JS, Li Y, Chen Y. Effects of exercise training and deconditioning on platelet aggregation induced by elternating shear stress in men. Arterioscler Thromb Vasc Biol. 2005; 25(2): 454-460.

12. $\mathrm{Li} \mathrm{N}, \mathrm{He} \mathrm{S}$. Platelet activity, coagulation and fibrinolysis during exercise in healthy males: effects of thrombin inhibition by argatroban and enoxaparin. Arteriosc Thromb and Vasc Biol. 2007; 27: 407-413.

13. Ghanbari Niaki A, Mohammadi S. Effect of 4 Weeks of an Aerobic (RAST) Training on Hematological Changes In Male Kick-Boxers. Journal of Applied Exercise Physiology (Journal of Sports Science). 20092010; 5(10): 75-87.[Persian]

14. Hoffman-Goetz L, Pedersen BK. Exercise and the immune system: A model of the stress response? Immunol Today. 1994; 15(8): 345-392.

15. Wu HJ, Chen KT, Shee BW, Chang HC, Huang YJ, Yang RS. Effects of 24 h ultra-marathon on biochemical and hematological parameters. World $\mathrm{J}$ Gastroenterol. 2004; 10(18): 2711-4.

16. Azadbakht L, Mirmiran P, Esmaillzadeh A, Azizi F. Dairy consumption is inversely associated with the prevalence of the metabolic syndrome in tehranian adults. The American journal of clinical nutrition. 2005; 82(3): 523-30.

17. Mcfarlin B, Mitchell J, Mcfarlin M, Steinhoff G. Repeated endurance exercise affects leukocyte number but not nkcell activity. Medicine \& Science in Sports \& Exercise. 2003; 35(7): 130-90.

18. Ebrahim Kh, Nurshahi M, Nassrabadi M. A Study of the Effect of Carbohydrate Supplementation Perior to a Maximal Exercise on the Number of White Blood Cells, Glucose and Cortisol in College Female Athletes. Harakat .2005; 25: 21-30. [Persian]

19. Satarifard S, Gaeini AA, Choobineh S. The Effect of Exercise on the Total Number of Blood Leukocytes and Platelets of the Athletes in Cold, Warm and Normal Temperature Conditions. Armaghane-danesh, Yasuj University of Medical Sciences Journal (YUMSJ) .2011; 16(5):433-443. [Persian]

20. Agha Alinejad H, Safarzadeh AR, Mlanvrdy M, Aisanejad A, Delfan M. Immune function in sport. 1st ed. Tehran: Hatmi publications.2012; 177-200. [Persian]

21. Hasani A, Soleimanian K. The effect of progressive endurance training and silymarin consumption on hematolofical parameters. Sci J Iran Blood Transfus Organ.2014; 11(2):155-163. [Persian]

22. Nikseresht A, Fehresti Haghighi Sh, Solhjoo K, Kargar Jahromy H. Effect of maximum activity on the immune system cells in diabetic rats. J Jahrom Univ Med Sci. 2013; 10(4):49-54. [Persian]

23. Hack V, Strobel G, Rau JP, Weicker H. The effect of maximal exercise on the activity of neutrophil granulocytes in highly trained athletes in a moderate training period. Eur J Appl Physiol Occup Physiol. 1992; 65(6): 520-4

24. Glesson M, Burton S, Cave R. Hematological Response to intermittent maximal exercise in man. Glasgoww Meeting. 1990; 61.

25. Gaeini AA. Hormonal and plasma volume changes after endurance trainings. Harakat. 1999; 1(1): 3956.[Persian]
26. Tayebi M, Agha Alinejad H, Kiadaliri K, Ghorbanalizadeh Ghaziani F. Assessment of $C B C$ in physical activity and sport: a brief review. Sci J Blood Transfus Organ. 2011; 7(4): 249-265. [Persian]

27. Flynn MG, Mackinnon L, Gedge V, Fahlman M, Brickman T. Influence of iron status and iron supple mentation on natural killer cell activity in trained women runners. Inter j sports med apr. 2003; 24(3): 217-22. DOI: $10.1055 / \mathrm{s}-2003-39095$.

28. Kondo S, Fuke T, Tokiwa M, Ryuu H, Yano J, Sakai $\mathrm{C}$, et al. The effects of fitness type exercise on iron status and hematological status for female college student. Rinsho Byori. 1995; 43(9): 953-959.

29. Haghighi AH, Shojae H, Hamedinia MR, Sardar MA. Effect of different volumes of aerobic trainings on iron status in young girls. JSPORT.pec. 2012;15(8): 67-82. [Persian]

30. Di Santolo M, Stel G, Banfi G, Gonano F, Cauci S. Anemia and iron status in young fertile non professional female athletes. Eur J Appl Physiol. 2008; 102(6): 703709.

31. Dubnov C, Naama W. Prevalence of iron depletion and Top-level Basketball players. Int $\mathrm{j}$ sport nut exer metab 2004; 14(1): 30-37.

32. Schumacher Y, Schmid A, Grath WD, Bulterman D, Berg A. Hematological indices and iron statusin athletes of various sports and performance. Med sci sports exerc. 2002; 34(5), 869-75.

33. Ricci G, Masotti M, De Paoli Vitali E, Vedovato M, Zanotti G. effects of exercise on haematologic parameters, serum iron, serum firritin, redcell 2,3 diphosphoglycerate and creatine contents, and serum erythropoietin in long-distance runners during basal training. acta haematol, 1988; 80(2), 95-8.

34. Ahmadizad S, El-Sayed MS. The effect of graded resistance exercise on platelet Aggregation and Activation. Med Sci Sports Exerc. 2003; 35(6): 1026-32. [Persian]

35. Kawano TA, Aoki N, Homori M, Kawano K, Maki A, Kimura M, et al. Mental stress and physical exercise increase platelet-depondent thrombin genrration. Heart Vessels. 2000; 15(6): 280-8.

36. Coppola L, Grassia A, Coppola A, Tondi G, Peluso $\mathrm{G}$, Mordente $\mathrm{S}$, et al. Effects of a moderate intensity aerobic program an blood viscosity, platelet aggregation and faibrinlonytic balance in young and middle aged sedentary subjects. Blood Coagul Fibrinlysis. 2004; 15(1): 31-37.

37. Wagner DD, Burger PC. Platelets in inflammation and thrombosis. Thromb Vasc Biol. 2003; 23(12): 21317.

38. Weyrich AS, Zimmerman GA. Platelets: signaling cells inside the immune continuum. Trends in Immunology. 2004; 25(9): 489-95.

39. Hulmi JJ, Myllymäki T, Tenhumäki M, Mutanen N, Puurtinen R, Paulsen G. Effects of resistance exercise and protein ingestion on blood leukocytes and platelets in young and older men. Eur J Appl Physiol. 2010; 109(2): 343-53. 
40. Tayebi SM, Ghorbanalizadeh Ghaziani F, Ghanbari Niaki A. Effects of a low intensity single session of circuit resistance exercise on hematologic variables in male physical education students. The 5th student's scientific congress on physical education and sport sciences. Mazandaran University of Baboulsar. 2007; 219. [Persian]

41. Tayebi SM, Ghorbanalizadeh Ghaziani F, GhanbariNiaki A, Esmaeilzadeh Tolo MR, Hakimi J. Effect of a single session of circuit resistance exercise on serum hematologic changes in male physical education students. the 3rd student's scientific congress on physical education and sport sciences. Ferdowsi university of Mashhad. 2005; 38. [Persian]

42. Ghanbari Niaki A, Tayebi SM, Ghorbanalizadeh Ghaziani F, Hakimi J. Effect of a single Session of Weight-Circuit Exercise on Hematological changes of Physical education Students. Journal of Sports Sciences. 2005; 1(2): 77-88. [Persian]

43. Yilmaz MB, Saricam E, Biyikoglu SF, Guray Y, Guray U, Sasmaz H, et al. Mean platelet volume and exercise stress test. J Thromb Thrombolysis. 2004; 17(2): 115- 20. 